Published in final edited form as:

Ann Intern Med. 2013 August 6; 159(3): 169-175. doi:10.7326/0003-4819-159-3-201308060-00006.

\title{
Mucosal Healing and Risk of Lymphoproliferative Malignancy in Celiac Disease
}

\author{
Benjamin Lebwohl, MD, $\mathbf{M S}^{1,2}$, Fredrik Granath, $\mathrm{PhD}^{2}$, Anders Ekbom, MD, $\mathrm{PhD}^{2}$, Karin \\ Ekström Smedby, MD, PhD ${ }^{2}$, Joseph A. Murray, MD ${ }^{3}$, Alfred I. Neugut, MD, PhD ${ }^{1}$, Peter HR \\ Green, $\mathrm{MD}^{1}$, and Jonas F. Ludvigsson, MD, PhD ${ }^{2,4,{ }^{*}}$ \\ ${ }^{1}$ Celiac Disease Center, Department of Medicine, Columbia University College of Physicians and \\ Surgeons, New York, New York, USA \\ ${ }^{2}$ Clinical Epidemiology Unit, Department of Medicine, Karolinska University Hospital and \\ Karolinska Institutet, Stockholm, Sweden \\ ${ }^{3}$ Division of Gastroenterology and Hepatology, Department of Medicine, Mayo Clinic College of \\ Medicine, Rochester, USA \\ ${ }^{4}$ Department of Pediatrics, Örebro University Hospital, Sweden
}

\begin{abstract}
Background-Celiac disease (CD) is associated with an increased risk of lymphoproliferative malignancy (LPM). It is unknown whether this risk is affected by the results of the follow-up intestinal biopsy, performed to document mucosal healing.
\end{abstract}

Objective-To examine the association between mucosal healing in CD and later LPM.

Design-Population-based cohort study

Setting-We identified patients with CD from all of Sweden's 28 pathology departments.

Patients-Individuals with $\mathrm{CD}$ who had a follow-up biopsy after initial diagnosis.

Measurements-We compared the risk of LPM to that of the general population using expected rates; and through Cox regression we compared the rate of LPM in those with persistent villous atrophy to those with mucosal healing.

\footnotetext{
"Correspondence and reprint requests: Jonas F. Ludvigsson, Department of Pediatrics, Örebro University Hospital, Sweden, Phone: +46 (0) 19- 6021000, Fax: +46 (0) 19-187915, jonasludvigsson@yahoo.com.

POSTAL ADDRESSES FOR ALL AUTHORS

Benjamin Lebwohl, MD, MS, The Celiac Disease Center at Columbia University, 180 Fort Washington Avenue, Suite 936, New York, NY 10032, USA

Fredrik Granath, PhD, Clinical Epidemiology Unit, Eugeniahemmet, T2, Karolinska Institutet, SE-171 76, Stockholm, Sweden Anders Ekbom, MD, PhD, Clinical Epidemiology Unit, Eugeniahemmet, T2, Karolinska Institutet, SE-171 76, Stockholm, Sweden Karin Ekström Smedby, MD, PhD, Clinical Epidemiology Unit, Eugeniahemmet, T2, Karolinska Institutet, SE-171 76, Stockholm, Sweden

Joseph A. Murray, MD, 200 1st St SW Mayo East 9, Rochester, MN 55905, USA

Alfred I. Neugut, MD, PhD, Mailman School of Public Health, 722 West $168^{\text {th }}$ Street, Room 725, New York, NY 10032

Peter HR Green, MD, The Celiac Disease Center at Columbia University, 180 Fort Washington Avenue, Suite 936, New York, NY 10032, USA

Jonas F. Ludvigsson, MD, PhD, Department of Pediatrics, Örebro University Hospital, SE-70185 Örebro, Sweden

Details of ethics approval: This project (2006/633-31/4) was approved by the Research Ethics Committee of the Karolinska Institute, Sweden on June $14^{\text {th }}, 2006$.

Conflicts of interest/Disclosure requirement

All authors declare that they have no conflicts of interest and nothing to declare.
} 
Results-Among 7,625 patients with CD and a follow-up biopsy, persistent villous atrophy was present in 3,308 (43\%). The overall risk of LPM was increased compared to the general population (Standardized incidence ratio, SIR 2.81; 95\%CI 2.10-3.67), but this increase was greater among those with persistent villous atrophy (SIR 3.78; 95\% CI 2.71-5.12) as compared to those with mucosal healing (SIR 1.50; 95\% CI 0.77-2.62). Persistent villous atrophy compared to mucosal healing was associated with an increased risk of LPM (Hazard ratio, HR 2.26; 95\% CI 1.18-4.34). We found an increased risk of T cell lymphoma (HR 3.51; 95\%CI 0.75-16.34), but no excess risk of B cell lymphoma (HR 0.97; 95\%CI 0.21-4.49).

Limitation-We had no data on dietary compliance.

Conclusions-The increased LPM risk in CD is associated with the results of the follow-up biopsy, with a higher risk among those with persistent villous atrophy. Follow-up biopsy may be a means to effectively stratify CD patients regarding subsequent LPM risk.

Primary funding source-the National Center for Advancing Translational Sciences, National Institutes of Health, The American Scandinavian Foundation, the Celiac Sprue Association, Örebro University Hospital, Karolinska Institutet, the Swedish Society of Medicine, the Swedish Research Council, and the Swedish Celiac Society.

\section{INTRODUCTION}

Celiac disease (CD) is a common autoimmune disease, affecting approximately $1 \%$ of individuals residing in Western nations. $(1,2)$ The prevalence of $\mathrm{CD}$, both diagnosed and undiagnosed, has increased substantially over the past half-century. $(3,4)$ Multiple studies have found an increased risk of lymphoproliferative malignancies (LPM) in patients with CD.(5-10) The risk of LPM declines over time after CD diagnosis, presumably due to the beneficial effects of diagnosis and treatment, with the elimination of gluten from the diet. This risk, though diminished, remains persistently elevated compared to the general population. $(5,10,11)$

The reason for this persistently elevated risk of LPM in CD is unknown, but may be due to persistent villous atrophy in a subset of patients. Although healing of the duodenal mucosa while adhering to a gluten-free diet has been historically considered a necessary component to diagnose $\mathrm{CD},(12)$ multiple studies in recent years have found that a substantial proportion of patients with serological and histological evidence of $\mathrm{CD}$ fail to show mucosal healing on follow-up biopsy.(13-20) Persistent villous atrophy is more common in patients whose adherence to the gluten-free diet is poor, $(14,16-19)$ and two studies described patients with persistent villous atrophy who subsequently developed significant morbidity, including osteoporosis and malignancy. $(14,20)$ However, these studies did not include a control $\operatorname{arm}(20)$ or did not quantify the risk of LPM.(14)

There is uncertainty regarding whether follow-up biopsy to confirm mucosal healing should be done routinely in patients with $\mathrm{CD}$, and published guidelines are contradictory on this question.(21) We, therefore, aimed to determine whether the presence of villous atrophy on follow-up biopsy is associated with the risk of subsequently developing LPM, compared to patients with $\mathrm{CD}$ who had mucosal healing on follow-up. We also aimed to quantify the risk of LPM for those patients with persistent villous atrophy and those with mucosal healing, compared to the general population.

\section{METHODS}

Between October 2006 and February 2008, we collected small intestinal biopsy report data from all of Sweden's 28 pathology departments.(22) Biopsy report data included personal identity number, date of biopsy, morphology, and topography (duodenum and jejunum). 
Biopsies had been performed in 1969-2008. CD was defined as having villous atrophy (equal to Marsh 3) according to the Swedish SnoMed classification. In an earlier validation study, upon manual screening of 1,534 biopsy reports, we found that comorbidity other than $\mathrm{CD}$ was rare (the most common comorbidity was inflammatory bowel disease which occurred in $0.3 \%$ ).(22) We then excluded individuals in whom the biopsy might potentially originate from the ileum and individuals with any other kind of data irregularities. The remaining individuals are identical to those in our study on mortality in $\operatorname{CD}(n=29,096)$. (23)

We identified all patients with biopsy-proven $\mathrm{CD}$ who underwent a follow-up biopsy to document mucosal healing. In order to maximize the probability that these patients underwent follow-up biopsy as a routine practice to document mucosal healing (rather than being prompted by a clinical event, such as a worsening of gastrointestinal symptoms), we excluded all patients whose follow-up biopsy was performed less than six months or more than five years after the initial diagnostic biopsy. We excluded all patients who developed LPM prior to the performance of the follow-up biopsy. Mucosal healing was defined as resolution of villous atrophy; since intraepithelial lymphocytosis and/or crypt hyperplasia often persists in the long term without clinical sequelae, patients with these findings on follow-up biopsy but without persistent villous atrophy were classified as healed.(24)

The occurrence of LPM was determined by matching this cohort to the Swedish National Cancer Registry, using the International Classification of Diseases (ICD) codes 200-204 including malignant lymphoma, multiple myeloma and acute and chronic lymphocytic leukemia. This grouping is compatible with the recent World Health Organization classification of lymphoproliferative malignancies.(25) Non-Hodgkin lymphomas were grouped into B-cell and T-cell types using Snomed codes; we only used data on B-cell and T-cell lymphoma types from the year 2000 and onwards since B-cell and T-cell lymphomas were difficult to distinguish with certainty before that time. We calculated Standardized Incidence Ratios (SIR) of the risk of LPM, using the population of Sweden as the reference. Expected rates of LPM were calculated based on the observation time by gender, age group (using 5-year age categories), and year. SIR's were calculated for the cohort overall, for those with mucosal healing, and for those with persistent villous atrophy; 95\% confidence intervals were calculated using the assumption that the observed incidence of LPM had a Poisson distribution.

We compared the risk of LPM of those with persistent villous atrophy compared to those with mucosal healing using Cox proportional hazards regression. Follow-up time began on the day of the second biopsy and ended on the day of death, emigration, a diagnosis of LPM, or December 31, 2009. We adjusted for the following covariates: age at follow-up biopsy, gender, duration of $\mathrm{CD}$ at the time of follow-up biopsy (i.e., length of time between initial biopsy and follow-up biopsy), calendar period, and degree of educational attainment. We subsequently repeated this adjusted Cox analysis, stratified by pathology department. We also report hazard ratios for the following LPM subtypes: non-Hodgkin lymphoma, B cell lymphoma, and T cell lymphoma. acute lymphocytic leukemia, chronic lymphocytic leukemia, and plasmacytoma/myeloma. Additionally, for a subset of patients, the degree of villous atrophy on the follow-up biopsy was further characterized as partial versus subtotal/ total villous atrophy, according to the classification system developed by Marsh and Oberhuber; $(26,27)$ we calculated separate hazard ratios for the association of partial and subtotal/total villous atrophy with LPM. We report absolute excess risk as calculated by $(1-[1 / \mathrm{HR}]) \times$ incidence per 100,000 person-years in the reference group.

So as to determine whether the risk of LPM changes over time after the performance of the follow-up biopsy, we conducted an additional analysis in which persistent villous atrophy was considered a time-dependent covariate, and we calculated hazard ratios as a function of 
time elapsed since the follow-up biopsy (during the first year, 1-5 years, and beyond five years after follow-up biopsy). Because the performance of the follow-up biopsy may be a consequence of (rather than a predictor of) LPM, we performed a series of sensitivity analyses, in which we began the at-risk period one month, three months, six months, and 12 months after the follow-up biopsy. In these sensitivity analyses, patients who developed LPM, died, or emigrated before this modified start-time were excluded. In additional sensitivity analyses, we re-defined the inclusion criteria, dividing the time window of follow-up biopsy into three narrower and non-overlapping time periods: <1 year, 1-2.99 years, and 3-5 years after diagnosis of CD.

We used the chi square test when comparing proportions of categorical variables. All reported $\mathrm{p}$ values are two sided, and we considered $\mathrm{p}$ values $<0.05$ to be statistically significant. All statistical calculations were performed using SAS (Cary, NC) version 9.2. This study was approved by the Research Ethics Committee of Karolinska Institutet, Stockholm, Sweden.

\section{Role of the Funding Source}

This study was funded by the National Center for Advancing Translational Sciences, National Institutes of Health; the American Scandinavian Foundation; the Celiac Sprue Association; Örebro University Hospital; Karolinska Institutet; the Swedish Society of Medicine; the Swedish Research Council; and the Swedish Celiac Society. The funder had no role in the study design, data collection, data analysis, or the decision to submit the manuscript for publication.

\section{RESULTS}

\section{Patient characteristics}

Of the 9,725 patients with biopsy-confirmed CD and a documented follow-up biopsy, 2,077 underwent a follow-up biopsy within six months or beyond five years after their initial diagnosis. Of the remaining 7,648 patients, 23 were excluded because of a diagnosis of LPM prior to the follow-up biopsy. The remaining 7,625 were included in the analysis.

Characteristics of the 7,625 patients are listed in Table 1. The median age at diagnosis was 25 years, and $63 \%$ of the patients were female. The median duration between diagnosis with $\mathrm{CD}$ and follow-up biopsy was 1.3 years. Persistent villous atrophy was present on follow-up biopsy in $43 \%$ of all patients.

Patients were followed for a median of 10.6 years after CD diagnosis, and 8.9 years after follow-up biopsy. More than 10 years of observation after follow-up biopsy were available in 3,357 individuals (44\%), including 1,626 patients (21\%) with more than 15 years of observation time.

\section{Celiac disease and LPM}

LPM developed in 53 patients, $0.7 \%$ of the cohort. Of the 53 patients who developed LPM, the median time to LPM was 4.9 years after follow-up biopsy. The 53 cases of LPM were diagnosed in patients who underwent small intestinal biopsy at 19 of the 28 pathology departments; the number of LPM cases diagnosed at each department ranged from 0 ( 9 departments) to 6 ( 2 departments). The overall incidence of LPM in this cohort was 67.9 per 100,000 person-years, yielding a SIR of 2.81 (95\% CI 2.10-3.67). 


\section{LPM risk according to mucosal appearance on follow-up biopsy}

Patients with persistent villous atrophy had an increased risk of LPM compared to the general population (incidence 102.4 per 100,000 person-years, SIR 3.78; 95\% CI 2.715.12). This increased risk was not as pronounced among those with mucosal healing (SIR $1.50 ; 95 \%$ CI 0.77-2.62).

On multivariate Cox analysis (Table 2), patients with persistent villous atrophy were at increased risk of developing LPM compared to patients with mucosal healing (HR 2.26; 95\% CI 1.18-4.34, absolute excess risk 57 per 100,000 person-years). This increased risk was most pronounced in the first year after follow-up biopsy (HR 3.67 95\% CI 0.80-16.86) as compared to the risk from one to five years after follow-up biopsy (HR 1.99; 95\% CI 0.63-6.31) and the risk beyond five years after follow-up biopsy (HR 1.99; 95\% CI 0.794.97). These differences in hazard ratios over time did not approach conventional levels of statistical significance ( $p>0.2)$. When we stratified by pathology department the risk of LPM was greater in patients with persistent villous atrophy compared to those with mucosal healing (HR 2.10; 95\% CI 1.08-4.12).

The risk of LPM, stratified by gender, age, and calendar period, is listed in Table 2 . The association between persistent villous atrophy and LPM risk was similar in men and women ( $\mathrm{p}$ for interaction $>0.2$ ). The association was stronger in patients older than 60 years at the time of follow-up biopsy (HR 2.41; 95\% CI 0.97-5.97) as compared to the younger age strata, though there were few events in patients younger than 40 years, and a formal test for interaction of age and persistent villous atrophy was not statistically significant ( $>0.2)$. For patients who underwent follow-up biopsy in the year 2000 and onward, the association between persistent villous atrophy and LPM was not seen (HR 1.05; 95\% CI 0.33-3.32). A test for statistical significance of the interaction term of calendar period and follow-up biopsy result on the outcome of LPM rate was not significant ( $p>0.2)$.

Risks of LPM subtypes are described in Table 3. Specific LPM subtypes that were increased among those with persistent villous atrophy included non-Hodgkin lymphoma (HR 2.82; 95\% 1.29-6.17). Within this group, there was a significantly increased risk of unspecified forms (HR 4.31; 95\% CI 1.27-14.61) and a suggestion of increased risk of T cell lymphoma (HR 3.51; 95\% CI 0.75-16.34).

Of the 3,308 patients with persistent villous atrophy on follow-up biopsy, the degree of villous atrophy was specified in 1,255 (38\%). Partial villous atrophy was reported in 712 $(57 \%)$ and subtotal or total villous atrophy was reported in 543 (43\%). The degree of villous atrophy was associated with a progressive increase in LPM risk. Patients with subtotal or total villous atrophy on follow-up biopsy had a greater increase in LPM risk (HR 3.96; 95\% 1.65-9.50) as compared to those with partial villous atrophy (HR 1.90; 95\% CI 0.70-5.19). This dose-response relationship was also observed with the outcome of T cell lymphoma, wherein patients with subtotal or total villous atrophy had 9-fold increased risk of $\mathrm{T}$ cell lymphoma (HR 9.23; 95\% CI 1.66-51.34) compared to a 3.4-fold increase in individuals with partial villous atrophy (HR 3.40; 95\% CI 0.55-20.91).

On sensitivity analysis, varying the start time of the at-risk period from one month to 12 months did not appreciably change the main association between persistent villous atrophy and LPM risk (Table 4). This association persisted when excluding the first 12 months of follow-up time after follow-up biopsy (HR 2.00; 95\% CI 0.97-4.13). When re-defining the follow-up biopsy window into narrower time periods, the magnitude of association between persistent villous atrophy and subsequent LPM was similar in the three sensitivity analyses (<1 year: HR 2.69; 95\% CI 1.02-7.08. 1-2.99 years: HR 2.01; 95\% CI 0.70-5.81. 3-5 years: HR 2.35; 95\% CI 0.29-19.57). 


\section{DISCUSSION}

In this population-based study of patients with $\mathrm{CD}$ who had a follow-up biopsy, we found an increased risk of LPM compared to the general population similar to that found in previous studies.(5-7) But this is the first study to evaluate the risk-stratifying effect of the follow-up biopsy: among those with persistent villous atrophy, the risk was heightened, while among those with mucosal healing this risk was less prominent and did not meet statistical significance. When compared to CD patients with mucosal healing, CD patients with persistent villous atrophy had an increased risk of LPM.

Earlier studies on the clinical consequences of persistent villous atrophy $(14,20)$ have been limited to outcomes such as osteoporosis and malignancy, and we are unaware of any study estimating HRs for LPM according to histopathology status of the follow-up biopsy. This analysis of follow-up biopsy results was, by necessity, limited to those CD patients who underwent a second biopsy after diagnosis. These patients were a minority in the populationbased database of Swedish patients with CD $(n=29,096)$, raising a concern for selection bias. Patients who underwent follow-up biopsy may be different in unmeasured yet important ways compared to those who did not undergo follow-up biopsy. This concern is mitigated by the finding in this study that the incidence of LPM among those who underwent follow-up biopsy was 67.9 per 100,000 person-years, nearly identical to the overall incidence of LPM among all patients with $\mathrm{CD}$ (regardless of the number of biopsies), which was 70.3 per 100,000 person-years in an earlier study based on the dataset of the current study.(5) These similar rates of LPM suggest that the underlying risk of LPM among those CD patients who underwent follow-up biopsy was similar to those CD patients who did not.

There was a tendency of diminished risk of LPM among patients with persistent villous atrophy over time. The LPM risk was greatest during the first year after follow-up biopsy (HR 3.67; 95\% CI 0.80-16.86), and was less pronounced during the following four years (HR 1.99; 95\% CI 0.63-6.31) and beyond five years after follow-up biopsy (HR 1.99; 95\% CI 0.79-4.97), although there was no statistically significant heterogeneity over time. There are several potential explanations for such a phenomenon. Multiple studies of morbidity and mortality associated with $\mathrm{CD}$ have found that the increased risk diminishes towards the null over time, $(23,28)$ and this has been attributed to the effect of the gluten-free diet. The risk of LPM in CD patients likewise diminishes with time, though it remains significantly elevated compared to that of the general population in the long term (HR five years after diagnosis 1.98; 95\% 1.49-2.63).(5) In some patients, persistent villous atrophy may reflect a gradual healing process, and a future biopsy may show mucosal healing.(14) In such patients, it would be expected that the long-term prognosis with regard to LPM risk should be similar to those with mucosal healing. While exposure to dietary gluten might be expected to cause a long-term risk increase, the follow-up biopsy is a "snapshot" that does not predict future long-term adherence. The result of the follow-up biopsy may spur the patient to improve dietary adherence, which will eventually diminish the increased risk of LPM compared to those who had mucosal healing. Lastly, while the results of the follow-up biopsy likely reflect recent dietary adherence, $(14,16-19)$ it will less accurately reflect adherence to the gluten-free diet in the long term, and thus may have a less pronounced differentiating effect on long term risk of LPM.

The association between persistent villous atrophy and LPM risk appeared to vary over calendar period (Table 2). There did not appear to be an association between persistent villous atrophy and LPM in the calendar period beginning in 2000. Follow-up time was not as long in this most recent time stratum (median follow-up was 5.8 years, as compared to 13.6 years for those whose follow-up biopsy was performed in the years 1990-1999 and 21.9 years for those whose follow-up biopsy occurred pre-1990). 
The association between persistent villous atrophy and LPM risk is strong and consistent in the two earlier calendar periods. In the years spanning 1990-1999, the hazard ratio (2.38) is similar to the overall analysis, and in the calendar period preceding 1990, the hazard ratio was not calculable due to the absence of any LPM in those with mucosal healing, leading to a denominator of zero. In order to estimate the risk, we performed a hypothetical data manipulation and changed one patient in the 1980's who had mucosal healing, assigning him a diagnosis of LPM. This resulted in a HR of 5.88 (95\% CI 0.76-45.82) for the time strata of pre-1990. Another possibility for the apparently null association between follow-up biopsy in the most recent calendar period is that it is a chance finding, as there were only 12 patients who developed LPM in this calendar period.

This study has several limitations. Details regarding dietary adherence were not collected, and it is therefore premature to conclude that the degree of dietary adherence impacts LPM risk.(29) However, since measurement of adherence to the gluten-free diet can be difficult and does not always correlate with serological data,(30) the result of the follow-up biopsy can be considered a more objective arbiter of adherence.(14, 16-19) Persistent villous atrophy may reflect minute gluten exposure that may not otherwise be known or reported by the patient,(31) and the finding of the present study, which shows an association between persistent villous atrophy and LPM risk, supports the practice of performing follow-up biopsy as a complement to dietary assessment. Reliable information regarding lymphoma subtype was not available before the year 2000, and thus the analysis of non-Hodgkin lymphoma subtypes (B versus T cell) included a large number of unclassified lymphomas. Nevertheless, there was an indication of a difference in risk of developing $\mathrm{T}$ cell lymphoma versus $\mathrm{B}$ cell lymphoma. We were unable to characterize $\mathrm{T}$ cell lymphomas as belonging to enteropathy-associated $\mathrm{T}$ cell lymphoma versus non-intestinal $\mathrm{T}$ cell lymphoma subtypes; the former entity has a close association with $\mathrm{CD}$, and may be rising in incidence. $(32,33)$ Earlier patient chart validation has shown that some $93 \%$ of second biopsies were traditional follow-up biopsies, but we cannot rule out that a proportion of what was regarded as followup biopsies were actually not true follow-up biopsies, but rather a third or a fourth biopsy, if the earliest biopsies of a patient had not been recorded in the computerized biopsy databases of Sweden. The economic implications of routine follow-up biopsy were not considered in this study, and a cost-benefit analysis regarding this approach is warranted. Strengths of this study include its population-based setting, and the extensive follow-up time, including $\geq 15$ years in more than $20 \%$ of the cohort.

As this was a database analysis without detailed clinical information regarding the indication for each biopsy, we were unable to rule out reverse causality as contributing in-part to the association between villous atrophy and LPM. It is possible that some patients developed persistent villous atrophy as a consequence of enteropathy-associated T cell lymphoma, and developed symptoms, prompting the follow-up biopsy. For this reason, we performed sensitivity analyses, restricting the observation period after the follow-up biopsy for varying periods up to one year. These restrictions (Table 4) did not result in substantial change of the main risk estimates.

Despite the fact that this study was based on more than 7,000 individuals undergoing followup biopsy, our statistical power may have been limited in some analyses. For instance we cannot rule out that individuals with mucosal healing $(\mathrm{SIR}=1.50)$ were at increased risk of LPM compared to the general population since the upper 95\%CI level attained 2.62 even if the $95 \%$ CI signaled statistical non-significance.

We conclude that the increased risk of LPM in CD may be affected by mucosal healing. The frequently-reported increased risk of LPM in CD is most pronounced among those patients who have persistent villous atrophy, and is less increased among those patients who have 
mucosal healing. Patients with persistent villous atrophy have a more than doubling of risk of LPM compared to those with mucosal healing (HR 2.26; 95\% 1.18-4.34). These findings support the end-point of mucosal healing as a goal for patients with $\mathrm{CD}$ so as to reduce their risk of LPM.

\section{Acknowledgments}

Grant Support (Funding)

BL: The American Scandinavian Foundation, the Celiac Sprue Association, and the National Center for Advancing Translational Sciences, National Institutes of Health, (KL2 TR000081)

AE: Stockholm County Council.

KES: The Strategic Research Program in Epidemiology Young Scholar Award

JAM: The National Institutes of Health - DK071003 and DK057892.

JFL: Örebro University Hospital, Karolinska Institutet, the Swedish Society of Medicine, the Swedish Research Council - Medicine (522-2A09-195) and the Swedish Celiac Society.

\section{References}

1. Green PH, Cellier C. Celiac disease. N Engl J Med. 2007; 357(17):1731-43. [PubMed: 17960014]

2. Mustalahti K, Catassi C, Reunanen A, Fabiani E, Heier M, McMillan S, et al. The prevalence of celiac disease in Europe: results of a centralized, international mass screening project. Ann Med. 2010; 42(8):587-95. [PubMed: 21070098]

3. Rubio-Tapia A, Kyle RA, Kaplan EL, Johnson DR, Page W, Erdtmann F, et al. Increased prevalence and mortality in undiagnosed celiac disease. Gastroenterology. 2009; 137(1):88-93. [PubMed: 19362553]

4. Catassi C, Kryszak D, Bhatti B, Sturgeon C, Helzlsouer K, Clipp SL, et al. Natural history of celiac disease autoimmunity in a USA cohort followed since 1974. Ann Med. 2010; 42(7):530-8.

[PubMed: 20868314]

5. Elfstrom P, Granath F, Ekstrom Smedby K, Montgomery SM, Askling J, Ekbom A, et al. Risk of lymphoproliferative malignancy in relation to small intestinal histopathology among patients with celiac disease. J Natl Cancer Inst. 2011; 103(5):436-44. [PubMed: 21289299]

6. Catassi C, Fabiani E, Corrao G, Barbato M, De Renzo A, Carella AM, et al. Risk of non-Hodgkin lymphoma in celiac disease. JAMA. 2002; 287(11):1413-9. [PubMed: 11903028]

7. Smedby KE, Akerman M, Hildebrand H, Glimelius B, Ekbom A, Askling J. Malignant lymphomas in coeliac disease: evidence of increased risks for lymphoma types other than enteropathy-type $\mathrm{T}$ cell lymphoma. Gut. 2005; 54(1):54-9. [PubMed: 15591504]

8. Askling J, Linet M, Gridley G, Halstensen TS, Ekstrom K, Ekbom A. Cancer incidence in a population-based cohort of individuals hospitalized with celiac disease or dermatitis herpetiformis. Gastroenterology. 2002; 123(5):1428-35. [PubMed: 12404215]

9. West J, Logan RF, Smith CJ, Hubbard RB, Card TR. Malignancy and mortality in people with coeliac disease: population based cohort study. BMJ. 2004; 329(7468):716-9. [PubMed: 15269095]

10. Green PH, Fleischauer AT, Bhagat G, Goyal R, Jabri B, Neugut AI. Risk of malignancy in patients with celiac disease. Am J Med. 2003; 115(3):191-5. [PubMed: 12935825]

11. Gao Y, Kristinsson SY, Goldin LR, Bjorkholm M, Caporaso NE, Landgren O. Increased risk for non-Hodgkin lymphoma in individuals with celiac disease and a potential familial association. Gastroenterology. 2009; 136(1):91-8. [PubMed: 18950631]

12. Ciclitira PJ, King AL, Fraser JS. AGA technical review on Celiac Sprue. American Gastroenterological Association. Gastroenterology. 2001; 120(6):1526-40. [PubMed: 11313324]

13. Lee SK, Lo W, Memeo L, Rotterdam H, Green PH. Duodenal histology in patients with celiac disease after treatment with a gluten-free diet. Gastrointest Endosc. 2003; 57(2):187-91. [PubMed: 12556782] 
14. Rubio-Tapia A, Rahim MW, See JA, Lahr BD, Wu TT, Murray JA. Mucosal recovery and mortality in adults with celiac disease after treatment with a gluten-free diet. Am J Gastroenterol. 2010; 105(6):1412-20. [PubMed: 20145607]

15. Bardella MT, Velio P, Cesana BM, Prampolini L, Casella G, Di Bella C, et al. Coeliac disease: a histological follow-up study. Histopathology. 2007; 50(4):465-71. [PubMed: 17448022]

16. Lanzini A, Lanzarotto F, Villanacci V, Mora A, Bertolazzi S, Turini D, et al. Complete recovery of intestinal mucosa occurs very rarely in adult coeliac patients despite adherence to gluten-free diet. Aliment Pharmacol Ther. 2009; 29(12):1299-308. [PubMed: 19302264]

17. Ciacci C, Cirillo M, Cavallaro R, Mazzacca G. Long-term follow-up of celiac adults on gluten-free diet: prevalence and correlates of intestinal damage. Digestion. 2002; 66(3):178-85. [PubMed: 12481164]

18. Collin P, Maki M, Kaukinen K. Complete small intestine mucosal recovery is obtainable in the treatment of celiac disease. Gastrointest Endosc. 2004; 59(1):158-9. [PubMed: 14740630]

19. Hutchinson JM, West NP, Robins GG, Howdle PD. Long-term histological follow-up of people with coeliac disease in a UK teaching hospital. QJM. 2010; 103(7):511-7. [PubMed: 20519276]

20. Kaukinen K, Peraaho M, Lindfors K, Partanen J, Woolley N, Pikkarainen P, et al. Persistent small bowel mucosal villous atrophy without symptoms in coeliac disease. Aliment Pharmacol Ther. 2007; 25(10):1237-45. [PubMed: 17451570]

21. Leffler D. Celiac disease diagnosis and management: a 46-year-old woman with anemia. JAMA. 2011; 306(14):1582-92. [PubMed: 21990301]

22. Ludvigsson JF, Brandt L, Montgomery SM, Granath F, Ekbom A. Validation study of villous atrophy and small intestinal inflammation in Swedish biopsy registers. BMC Gastroenterol. 2009; 9:19. [PubMed: 19284576]

23. Ludvigsson JF, Montgomery SM, Ekbom A, Brandt L, Granath F. Small-intestinal histopathology and mortality risk in celiac disease. JAMA. 2009; 302(11):1171-8. [PubMed: 19755695]

24. Tuire I, Marja-Leena L, Teea S, Katri H, Jukka P, Paivi S, et al. Persistent duodenal intraepithelial lymphocytosis despite a long-term strict gluten-free diet in celiac disease. Am J Gastroenterol. 2012; 107(10):1563-9. [PubMed: 22825364]

25. Campo E, Swerdlow SH, Harris NL, Pileri S, Stein H, Jaffe ES. The 2008 WHO classification of lymphoid neoplasms and beyond: evolving concepts and practical applications. Blood. 2011; 117(19):5019-32. [PubMed: 21300984]

26. Marsh MN. Gluten, major histocompatibility complex, and the small intestine. A molecular and immunobiologic approach to the spectrum of gluten sensitivity ('celiac sprue'). Gastroenterology. 1992; 102(1):330-54. [PubMed: 1727768]

27. Oberhuber G, Granditsch G, Vogelsang H. The histopathology of coeliac disease: time for a standardized report scheme for pathologists. Eur J Gastroenterol Hepatol. 1999; 11(10):1185-94. [PubMed: 10524652]

28. Logan RF, Rifkind EA, Turner ID, Ferguson A. Mortality in celiac disease. Gastroenterology. 1989; 97(2):265-71. [PubMed: 2744350]

29. Olen O, Askling J, Ludvigsson JF, Hildebrand H, Ekbom A, Smedby KE. Coeliac disease characteristics, compliance to a gluten free diet and risk of lymphoma by subtype. Dig Liver Dis. 2011; 43(11):862-8. [PubMed: 21880561]

30. Leffler DA, Dennis M, Edwards George JB, Jamma S, Magge S, Cook EF, et al. A simple validated gluten-free diet adherence survey for adults with celiac disease. Clin Gastroenterol Hepatol. 2009; 7(5):530-6. [PubMed: 19268725]

31. Biagi F, Campanella J, Martucci S, Pezzimenti D, Ciclitira PJ, Ellis HJ, et al. A milligram of gluten a day keeps the mucosal recovery away: a case report. Nutr Rev. 2004; 62(9):360-3. [PubMed: 15497770]

32. Cellier C, Delabesse E, Helmer C, Patey N, Matuchansky C, Jabri B, et al. Refractory sprue, coeliac disease, and enteropathy-associated T-cell lymphoma. French Coeliac Disease Study Group. Lancet. 2000; 356(9225):203-8. [PubMed: 10963198]

33. Sharaiha RZ, Lebwohl B, Reimers L, Bhagat G, Green PH, Neugut AI. Increasing incidence of enteropathy-associated T-cell lymphoma in the United States, 1973-2008. Cancer. 2012; 118(15): 3786-92. [PubMed: 22169928] 
Table 1

Characteristics of patient cohort with CD and follow-up biopsies.

\begin{tabular}{|c|c|}
\hline Characteristic & Number (\%) \\
\hline \multicolumn{2}{|l|}{ Age at diagnosis of CD (years) } \\
\hline $0-19$ & $3508(46)$ \\
\hline $20-39$ & $1367(18)$ \\
\hline $40-59$ & $1672(22)$ \\
\hline 260 & $1078(14)$ \\
\hline Male & $2808(37)$ \\
\hline Female & $4817(63)$ \\
\hline \multicolumn{2}{|l|}{ Interval between diagnosis and follow-up biopsy } \\
\hline 6 months-1 year & $2019(26)$ \\
\hline Between 1 and 2 years & $3419(45)$ \\
\hline $2-5$ years & $2187(29)$ \\
\hline \multicolumn{2}{|l|}{ Calendar period of follow-up biopsy } \\
\hline$\leq 989$ & $728(10)$ \\
\hline 1990-1999 & $2885(37)$ \\
\hline$\geq 2000$ & $4012(53)$ \\
\hline \multicolumn{2}{|l|}{ Second biopsy result } \\
\hline Mucosal healing & $4317(57)$ \\
\hline Persistent villous atrophy & $3308(43)$ \\
\hline Developed lymphoproliferative malignancy & $53(0.7)$ \\
\hline
\end{tabular}

$\mathrm{CD}=$ Celiac Disease 
Table 2

Association of persistent villous atrophy with LPM stratified by gender, age, and year of celiac disease diagnosis.

\begin{tabular}{|c|c|c|c|}
\hline Stratum & Number of events & $\begin{array}{l}\text { Adjusted }{ }^{\dagger} \\
\text { HR }(95 \% \text { CI })\end{array}$ & p value \\
\hline \multicolumn{4}{|l|}{ Overall } \\
\hline Mucosal healing & 12 & 1.0 & \\
\hline Persistent villous atrophy & 41 & $2.26(1.18-4.34)$ & 0.015 \\
\hline \multicolumn{4}{|l|}{ Gender } \\
\hline \multicolumn{4}{|l|}{ Male } \\
\hline Mucosal healing & 6 & 1.0 & \\
\hline Persistent villous atrophy & 22 & $2.03(0.81-5.08)$ & 0.128 \\
\hline \multicolumn{4}{|l|}{ Female } \\
\hline Mucosal healing & 6 & 1.0 & \\
\hline Persistent villous atrophy & 19 & $2.45(0.96-6.24)$ & 0.061 \\
\hline \multicolumn{4}{|l|}{ Age at follow-up biopsy } \\
\hline \multicolumn{4}{|l|}{$<20$} \\
\hline Mucosal healing & 1 & 1.0 & \\
\hline Persistent villous atrophy & 1 & $0.78(0.04-14.49)$ & $>0.2$ \\
\hline \multicolumn{4}{|l|}{$20-39$} \\
\hline Mucosal healing & 0 & 1.0 & \\
\hline Persistent villous atrophy & 2 & * & $*$ \\
\hline \multicolumn{4}{|l|}{$40-59$} \\
\hline Mucosal healing & 5 & 1.0 & \\
\hline Persistent villous atrophy & 15 & $1.85(0.65-5.27)$ & $>0.2$ \\
\hline \multicolumn{4}{|l|}{260} \\
\hline Mucosal healing & 6 & 1.0 & \\
\hline Persistent villous atrophy & 23 & $2.41(0.97-5.97)$ & 0.058 \\
\hline \multicolumn{4}{|l|}{ Calendar Year } \\
\hline \multicolumn{4}{|l|}{1989 and before } \\
\hline Mucosal healing & 0 & 1.0 & \\
\hline Persistent villous atrophy & 11 & $*$ & $*$ \\
\hline \multicolumn{4}{|l|}{ 1990-1999 } \\
\hline Mucosal healing & 6 & 1.0 & \\
\hline Persistent villous atrophy & 24 & $2.38(0.96-5.87)$ & 0.060 \\
\hline \multicolumn{4}{|l|}{2000 and after } \\
\hline Mucosal healing & 6 & 1.0 & \\
\hline Persistent villous atrophy & 6 & $1.05(0.33-3.32)$ & $>0.2$ \\
\hline
\end{tabular}

HR = Hazard Ratio; LPM = Lymphoproliferative Malignancy

${ }^{\dagger}$ Hazard Ratios (HR) are adjusted for patient age, gender, calendar period of diagnosis, education, and duration of celiac disease at the time of follow-up biopsy. 
Unable to calculate due to 0 events in mucosal healing group 
Table 3

Risk of LPM subtypes in patients with celiac disease, according to mucosal healing status.

\begin{tabular}{|l|l|l|l|}
\hline Outcome & Number of events & $\begin{array}{l}\text { Adjusted } \\
\text { HR (95\% CI) }\end{array}$ & p value \\
\hline $\begin{array}{l}\text { All lymphoproliferative malignancies } \\
\text { Mucosal healing }\end{array}$ & 53 & & \\
Persistent villous atrophy & 41 & $2.26(1.18-4.34)$ & 0.015 \\
\hline $\begin{array}{l}\text { Non-Hodgkin lymphoma } \\
\text { Mucosal healing }\end{array}$ & 42 & & \\
Persistent villous atrophy & 34 & $2.82(1.29-6.17)$ & 0.009 \\
\hline B cell lymphoma & 7 & & \\
$\begin{array}{l}\text { Mucosal healing } \\
\text { Persistent villous atrophy }\end{array}$ & 3 & $0.97(0.21-4.49)$ & $>0.2$ \\
\hline T cell lymphoma & 12 & & 0.019 \\
$\begin{array}{l}\text { Mucosal healing } \\
\text { Persistent villous atrophy }\end{array}$ & 2 & & \\
\hline Unspecified Non-Hodgkin lymphoma & 23 & $3.51(0.75-16.34)$ & 0.110 \\
$\begin{array}{l}\text { Mucosal healing } \\
\text { Persistent villous atrophy }\end{array}$ & 20 & & \\
\hline
\end{tabular}

HR = Hazard Ratio; LPM = Lymphoproliferative Malignancy

${ }^{\dagger}$ Hazard Ratios (HR) are adjusted for the same covariates as in Table 2. 
Table 4

Sensitivity analyses, excluding progressively increasing durations after follow-up biopsy.

\begin{tabular}{|c|c|c|c|}
\hline Inclusion Criterion & Number of events & $\begin{array}{l}\text { Adjusted* } \\
\text { HR (95\% CI) }\end{array}$ & p value \\
\hline Include all patients & 53 & & \\
\hline Mucosal healing & 12 & & \\
\hline Persistent villous atrophy & 41 & $2.26(1.18-4.34)$ & 0.015 \\
\hline Begin follow-up after 1 month & 52 & & \\
\hline Mucosal healing & 11 & & \\
\hline Persistent villous atrophy & 41 & $2.47(1.26-4.86)$ & 0.009 \\
\hline Begin follow-up after 3 months & 47 & & \\
\hline Mucosal healing & 11 & & \\
\hline Persistent villous atrophy & 36 & $2.17(1.09-4.30)$ & 0.028 \\
\hline Begin follow-up after 6 months & 44 & & \\
\hline Mucosal healing & 11 & & \\
\hline Persistent villous atrophy & 33 & $1.96(0.98-3.93)$ & 0.057 \\
\hline Begin follow-up after 12 months & 41 & & \\
\hline Mucosal healing & 10 & & \\
\hline Persistent villous atrophy & 31 & $2.00(0.97-4.13)$ & 0.061 \\
\hline
\end{tabular}

HR = Hazard Ratio

*Hazard Ratios (HR) are adjusted for the same covariates as in Table 2. 